\title{
Externalizing behaviors in preadolescents: familial risk to externalizing behaviors and perceived parenting styles
}

\author{
Cathelijne J. M. Buschgens • Marcel A. G. van Aken • Sophie H. N. Swinkels • \\ Johan Ormel • Frank C. Verhulst • Jan K. Buitelaar
}

Received: 30 January 2009/Accepted: 14 December 2009/Published online: 30 December 2009

(C) The Author(s) 2009. This article is published with open access at Springerlink.com

\begin{abstract}
The aim was to investigate the contribution of familial risk to externalizing behaviors (FR-EXT), perceived parenting styles, and their interactions to the prediction of externalizing behaviors in preadolescents. Participants were preadolescents aged 10-12 years who participated in TRAILS, a large prospective populationbased cohort study in the Netherlands $(N=2,230)$. Regression analyses were used to determine the relative contribution of FR-EXT and perceived parenting styles to parent and teacher ratings of externalizing behaviors. FREXT was based on lifetime parental externalizing psychopathology and the different parenting styles (emotional warmth, rejection, and overprotection) were based on the child's perspective. We also investigated whether different dimensions of perceived parenting styles had different effects on subdomains of externalizing behavior. We found
\end{abstract}

C. J. M. Buschgens $(\bowtie)$ · S. H. N. Swinkels · J. K. Buitelaar Department of Psychiatry, Radboud University,

Nijmegen Medical Centre, PO Box 9101, HP 966, 6500 HB

Nijmegen, The Netherlands

e-mail: C.Buschgens@psy.umcn.nl

\section{A. G. van Aken}

Department of Developmental Psychology, Utrecht University, Utrecht, The Netherlands

S. H. N. Swinkels · J. K. Buitelaar

Karakter Child and Adolescent Psychiatry University Centre, Nijmegen, The Netherlands

J. Ormel

Department of Psychiatry, University of Groningen, Groningen,

The Netherlands

F. C. Verhulst

Department of Child and Adolescent Psychiatry,

Erasmus MC-Sophia, Rotterdam, The Netherlands main effects for FR-EXT (vs. no FR-EXT), emotional warmth, rejection, and overprotection that were fairly consistent across rater and outcome measures. More specific, emotional warmth was the most consistent predictor of all outcome measures, and rejection was a stronger predictor of aggression and delinquency than of inattention. Interaction effects were found for FR-EXT and perceived parental rejection and overprotection; other interactions between FR-EXT and parenting styles were not significant. Correlations between FR-EXT and perceived parenting styles were absent or very low and were without clinical significance. Predominantly main effects of FR-EXT and perceived parenting styles independently contribute to externalizing behaviors in preadolescents, suggesting FREXT and parenting styles to be two separate areas of causality. The relative lack of gene-environment interactions may be due to the epidemiological nature of the study, the preadolescent age of the subjects, the measurement level of parenting and the measurement level of FREXT, which might be a consequence of both genetic and environmental factors.

Keywords Externalizing behavior - Familial risk · Perceived parenting style - Gene-environment .

Correlation · Gene-environment interaction

\section{Introduction}

The importance of nature (genetic vulnerability) and nurture (environment) in the development of behavioral traits has been widely accepted over the last 50 years [28]. In recent years, the interest of researchers in developmental psychopathology has shifted from assessing the relative contribution of genetic and environmental influences to 
investigating the role of gene-environment correlation and gene-environment interaction in the causation of developmental psychopathology.

The results of twin and adoption studies suggest that genetic factors contribute to the development of externalizing behaviors $[13,14,31,42]$, with heritability estimates of between 0.51 and 0.80 for broad externalizing behaviors, and of about 0.75 for attention problems and overactivity. However, many risk factors, including genetic factors, are not disorder-specific $[14,16]$. High levels of comorbidity among ADHD, ODD and CD are found [8], which is likely to be due to a substantial degree of shared genetic liability, either operating directly, or indirectly through gene-environment correlations or interactions [24]. After controlling for the overlap between internalizing and externalizing symptoms, familial risk to externalizing behaviors (FREXT) is specifically associated with externalizing but not with internalizing psychopathology in the offspring [26]. In line with earlier studies $[9,25,26,43]$, we used a proxy for familial risk, which was based on data concerning life time parental externalizing psychopathology. Since the heritability of externalizing disorders is relatively high, and the etiologic contribution of common environmental risk factors to externalizing disorders is relatively modest, we may assume that mostly genetic factor drive the FR-EXT measure. Note that this familial risk might be a consequence of both genetic and environmental factors [39].

However, environmental influences (e.g. parenting styles) are also important to the causation of externalizing behaviors. A myriad of parenting styles and dimensions has been extensively studied since the 1930s [41]. As documented in several influential reviews [18], warm and accepting parenting styles are consistent predictors of favorable developmental outcomes in children, whereas hostility and rejection predict unfavorable outcomes. Adolescents who perceived a lack of parental warmth and high levels of rejection and overprotection exhibited more broad-band externalizing behaviors, aggressive behaviors, and delinquent behaviors [35]. Furthermore, perceived parental rejection was found to be the strongest predictor of the level of hostility in adolescents and adults [20], and of aggression/delinquency and attention problems [4].

Socialization research has mainly focused on finding connections between variation in child rearing and behavioral outcome in genetically related parent-child dyads. However, these associations between child-rearing styles and behavioral outcomes may be "spurious" (noncausal) [34] because genetic effects may cloud the interpretation of findings. First, the effect of genetic risk can be indirect, indicating that the effect of poor parenting may actually be the effect of susceptibility genes, or vice versa [27, 36]. The results of child-centered studies suggest that (retrospectively) perceived rearing styles are genetically influenced [29, 32, 33]. More specific, perceptions related to warmth in the family are genetically affected to a greater extent than perceptions of control. Second, children may differ-as a function of their personality and/or FR-in their susceptibility to rearing influences [6]; indicating heightened susceptibility to the negative effects of risky environments and to the beneficial effects of supportive environments $[5,6]$. Therefore, research on gene-environment interaction effects of parenting and child characteristics may provide more insight into the complexity of child development.

In this study, we aimed to replicate and extend earlier research regarding the effects of FR-EXT and parenting styles on externalizing behaviors. We used the child's perspective of parenting practices, because the child's beliefs about parental behavior seem to have more influence on its social adjustment than the parents' perspective of their own parenting behavior [12]. In order to avoid shared rater effects, we used parent's and teacher's evaluation of externalizing behaviors. By using measures for FR-EXT and perceived parenting styles in the same model, we could control for genetic influences on parenting and determine whether FR-EXT affects the way children respond to given environmental conditions [30]. Furthermore, many studies have focused on gene-environment interaction in antisocial behavior [21] and less in other domains of externalizing psychopathology. We attempted to answer the following questions:

1. does FR-EXT increase the risk of externalizing behaviors,

2. do perceived parenting styles [(lack of) emotional warmth, rejection, and overprotection] increase the risk of externalizing behaviors, and is a specific parenting style associated with specific externalizing behaviors, and

3. are children who have a FR-EXT differential susceptible to specific parenting styles with regard to externalizing behaviors?

\section{Methods}

Sample

The subjects were participants of the TRacking Adolescents' Individual Lives Survey (TRAILS), a prospective cohort study of Dutch preadolescents who will be measured biennially until they are at least 25 years old. The key objective of TRAILS is to chart and explain the development of mental health from preadolescence into adulthood, in terms of underlying vulnerability and environmental risk. Participants were 10 to 12 years old and lived in the 
three largest cities and some rural areas in the north of the Netherlands. A detailed description of the sampling procedure and methods is provided elsewhere [11].

Briefly, the present study involves the first assessment wave of TRAILS, which ran from March 2001 to July 2002 [9, 11, 25, 43]. Of all children approached for enrollment in the study (i.e., children selected by the municipalities and attending a school that was willing to participate; $N=3,145$ children from 122 schools, with $90.4 \%$ of the schools responding), $6.7 \%$ were excluded because of incapability or language problems. Of the remaining 2,935 children, $76.0 \%$ were enrolled in the study, yielding a sample size of 2,230. Both the child and the parent consented to participate. The mean age of the children was 11.09 years $(\mathrm{SD}=0.55), 50.8 \%$ were girls, $10.3 \%$ were children who had at least one parent born in a non-Western country, and $32.6 \%$ of children had parents with a low educational level (i.e., a lower track of secondary education was the highest level attained). Responders and non-responders did not differ with respect to the prevalence rates of psychopathology and associations between sociodemographic variables and mental health outcomes [11].

\section{Data collection}

Well-trained interviewers visited one of the parents (preferably the mother, $95.6 \%$ ) at home to administer an interview covering a wide range of topics, including the child's developmental history and somatic health, parental psychopathology, and care utilization. Besides the interview, the parent was also asked to fill out a written questionnaire. Children were evaluated at school, where they filled out questionnaires in groups, under the supervision of TRAILS assistants, and were assessed individually. Teachers were asked to fill out a brief questionnaire for each TRAILS child in their class. Measures that were used in the present study are described below.

\section{Familial risk to externalizing behaviors (FR-EXT)}

Five dimensions of lifetime parental psychopathology were assessed (depressive disorders, anxiety disorders, substance dependence, antisocial behavior, and psychosis), using the TRAILS Family History Interview (FHI), which was administered at the parent interview [26]. Each dimension was introduced with a vignette describing the main DSM-IV [3] characteristics of the psychopathology, followed by a series of questions to assess lifetime occurrence, professional treatment, and medication use. Both biological parents were assessed during the interview, using a single informant, typically the mother. For each spectrum, the parents were assigned to one of the categories $0=$ (probably) never had an episode, $1=$ (probably) yes, or $2=$ (probably) yes and treatment and/or medication were provided. For antisocial behavior, the last category was $2=$ (probably) yes and picked up by the police. Prevalence rates in mother and fathers, respectively, were, for depression 27 and $15 \%$, for anxiety 16 and $6 \%$, for substance dependence 3 and $7 \%$, and for antisocial behavior 3 and 7\%. The FHI rates were by and large comparable to the CIDI-DSM-IV lifetime rates obtained by direct interviewing in NEMESIS [7]; the exception being fathers' rates for anxiety disorder and substance dependence that were $40 \%$ too low $[9,26,43]$. We did not focus on parental psychosis, depressive and anxiety disorders.

The construction of FR-EXT was based on the reported path coefficients regarding substance abuse and antisocial behavior by Kendler et al. [16], who performed multivariate twin modeling to investigate the structure of genetic risk for common psychiatric and substance use disorders. Since twin studies provide compelling evidence that the familial transmission of alcohol and drug dependence and adult antisocial behavior is attributable to a highly heritable general vulnerability that contributes to a spectrum of externalizing behaviors $\left(h^{2}=0.80\right)[10,14,16]$, we combined the coefficients reported by Kendler et al. [16] for alcohol dependence and drug abuse/dependence to create the variable substance abuse/dependence (SAD), and likewise we created the variable antisocial behavior (ASB) by combining the coefficients for antisocial behavior and conduct disorder. Subsequently, FR-EXT scores were computed by filling in the following regression equation: FR-EXT for externalizing behaviors $=\mathrm{SAD}$ mother + SAD father + ASB mother + ASB father, FR-EXT ranged from 0 to 8 (skewness 3.78, kurtosis, 17.63). The empirical justification for the construction of FR-EXT is provided elsewhere [26]. To enhance comparison with other TRAILS reports [9, 25, 43], missing values $(N=67)$ were replaced by the sample mean (0.18). Two groups were created on the basis of the distribution of FR-EXT (total $N=2,230$ ); children with no FR-EXT (82.2\%) and children with FR-EXT (17.8\%). In the regression analyses, these two groups were used as a dummy variable.

\section{Perceived parenting styles}

The Egna Minnen Beträffande Uppfostran (My Memories of Upbringing) for Children [EMBU-C] [19] was developed to assess children's and adolescents' perception of parents' rearing practices. The original EMBU-C contained 81 items. Markus et al. [19] developed a shorter version, which we used but without the favoring subject factor. We omitted this scale prior to administration, due to an internal consistency below 0.60. Each item, scored on a 4-point scale $(1=$ no, never, $2=$ yes, sometimes, $3=$ yes, often, 
4 = yes, almost always), was presented for both the father and the mother. The EMBU-C contains the factors emotional warmth, rejection, and overprotection. The main concepts of emotional warmth are giving special attention, praising approved behavior, unconditional love, and being supportive/affectionately demonstrative. An example of an item is: 'Do your parents make it obvious that they love you?'. Rejection is characterized by hostility, punishment (physical or not, abusive or not), and derogation and blaming of the child. An example of an item is: 'Do your parents sometimes punish you even though you haven't done anything wrong?' Overprotection is characterized by fearfulness and anxiety for the child's safety, guilt engendering, and intrusiveness. An example of an item is: 'Are your parents concerned about what you do after school hours?'

Principal component analysis with three factors (emotional warmth, rejection and overprotection) as criterion, followed by VARIMAX rotation, mainly confirmed the results by Markus et al. [19]. All items loaded on the designated scale, with the exception of five items of the rejection scale (the items $8,24,35,71$, and 76 in the article of Markus et al. [19], which were rejected because they had loadings lower than 0.30 or had a loading that differed by less than 0.10 with the second highest loading. In the study by Markus et al. [19], the items had relatively low loadings, on average 0.36 . The three factors explained 34.0 and $32.5 \%$ of the variance in the ratings on fathers and mothers.

The scale for emotional warmth contained 18 items with $\alpha=0.91$ for both fathers and mothers; the rejection scale contained 12 items with $\alpha=0.84$ for fathers and $\alpha=0.83$ for mothers, and the overprotection scale contained 12 items with $\alpha=0.70$ for fathers and $\alpha=0.71$ for mothers. The answers for both fathers and mothers were highly correlated $(r=0.79$ for emotional warmth, 0.67 for rejection, and 0.81 for overprotection), so we felt it was justified to combine them. The test-retest stability of a shortened version of the EMBU-C (10-item scales) over a 2-month period is satisfactory, $r \mathrm{~s}=0.78$ or higher [22]. Earlier studies have reported on the validity and cross-cultural equivalence of the EMBU-C [19].

\section{Externalizing behaviors}

Externalizing behaviors were assessed with the Child Behavior Checklist (CBCL), one of the most commonly used questionnaires in current child and adolescent psychiatric research $[1,44]$. It contains a list of 112 behavioral and emotional problems which parents can rate as $0=$ not true, $1=$ somewhat or sometimes true, or $2=$ very often true in the past 6 months. In addition to the CBCL, we administered the Teacher's Checklist of Psychopathology (TCP). The TCP contains descriptions of problem behaviors corresponding to the syndromes scored with Achenbach's Teacher Report [11]. Response options range from 0 (not applicable) to 4 (very clearly or frequently applicable). In this study, we focused on the CBCL syndromes attention problems $(\alpha=0.81)$, aggressive behavior $(\alpha=0.89)$, and delinquent behavior $(\alpha=0.68)$. Consistent with other reports [2], the agreement between parent-reported and teacher-reported problems was only moderate $(r=0.47$ for inattention, $r=0.37$ for impulsivity/hyperactivity, $r=0.32$ for aggression and $r=0.27$ for delinquency). We feel that the two informants perceive different aspects of problem behavior and that differences between informants are meaningful.

Statistical analyses

To obtain comparable regression coefficients, $z$ scores were used for all dependent variables and parenting style variables. All analyses were performed using the Statistical Package for the Social Sciences (SPSS for Windows, version 14.0).

Sex differences were examined by means of $t$ tests; associations between variables by means of Pearson correlations. Multiple linear regression analyses were used to determine the relative contribution of FR-EXT, emotional warmth, rejection, overprotection and gender to parents' and teachers' ratings of inattention, hyperactivity/impulsivity, aggression, and delinquency. Interaction terms between FR-EXT and perceived parenting styles were also entered into the regression models.

Multicollinearity was not present in our data (greatest VIF value is 1.81 for the predictor parental rejection).

All analyses were repeated without implementing FREXT data. The results of the $t$ tests, Pearson correlations, multiple regression analyses were largely comparable. This indicates that the likelihood of a bias due to implementing data is small [15].

\section{Results}

\section{Descriptives}

Table 1 contains means and standard deviation of FR-EXT, parent- and teacher-rated externalizing behaviors and perceived parenting styles, separately for boys and girls. Except for FR-EXT, all variables showed significant sex differences. Boys scored higher on all behavioral domains, indicating more problem behavior. Girls perceived more emotional warmth, and less rejection and less overprotection than boys. 
Table 1 Sex differences in familial risk to externalizing behaviors, perceived parenting styles and externalizing behavior

\begin{tabular}{|c|c|c|c|c|c|c|c|c|c|}
\hline \multirow[t]{2}{*}{ Variable } & \multicolumn{3}{|l|}{ Boys } & \multicolumn{3}{|l|}{ Girls } & \multicolumn{3}{|c|}{ Difference } \\
\hline & $M$ & SD & $N$ & $M$ & SD & $N$ & $T$ & $d f$ & $p$ \\
\hline FR-EXT vs. no FR-EXT & 0.15 & 0.36 & 1,056 & 0.15 & 0.36 & 1,107 & 0.02 & 2,161 & 0.89 \\
\hline Emotional warmth & -0.10 & 1.02 & 1,082 & 1.00 & 0.97 & 1,124 & 23.33 & 2,204 & $<0.001$ \\
\hline Rejection & 0.11 & 1.06 & 1,082 & -1.09 & 0.93 & 1,123 & 27.33 & 2,203 & $<0.001$ \\
\hline Overprotection & 0.06 & 1.03 & 1,082 & -0.06 & 0.97 & 1,123 & 7.97 & 2,203 & $<0.01$ \\
\hline CBCL inattention & 0.17 & 1.03 & 1,010 & -0.17 & 0.94 & 1,043 & 60.88 & 2,051 & $<0.001$ \\
\hline CBCL aggression & 0.14 & 1.07 & 1,011 & -0.13 & 0.91 & 1,043 & 37.43 & 2,052 & $<0.001$ \\
\hline CBCL delinquency & 0.20 & 1.11 & 1,011 & -0.19 & 0.84 & 1,043 & 82.86 & 2,052 & $<0.001$ \\
\hline TCP inattention & 0.20 & 1.07 & 934 & -0.19 & 0.89 & 993 & 76.83 & 1,925 & $<0.001$ \\
\hline TCP hyperactivity & 0.29 & 1.13 & 935 & -0.28 & 0.76 & 993 & 169.81 & 1,926 & $<0.001$ \\
\hline TCP aggression & 0.25 & 1.24 & 934 & -0.23 & 0.80 & 992 & 116.92 & 1,924 & $<0.001$ \\
\hline TCP delinquency & 0.19 & 1.19 & 934 & -0.18 & 0.73 & 992 & 70.42 & 1,924 & $<0.001$ \\
\hline
\end{tabular}

$F R$-EXT familial risk to externalizing behaviors, $C B C L$ child behavior checklist, $T C P$ teacher's checklist of psychopathology

Bivariate correlations between predictors and externalizing behaviors

Pearson correlations between the predictors (FR-EXT, emotional warmth, rejection, overprotection, and gender) and the dependent measures are summarized in Table 2. FR-EXT, rejection and overprotection were positively correlated with all dependent variables. Thus children with higher levels of FR-EXT showed more externalizing behaviors, as did children with higher levels of parental rejection and overprotection. Emotional warmth was negatively correlated with all dependent variables, indicating that children who perceived less parental emotional warmth showed more problem behavior, or conversely, children who perceived more parental warmth showed less problem behavior.

FR-EXT was not related to emotional warmth or rejection, but was very weakly related to overprotection $(r=0.04)$, which indicates that there was no gene-environment correlation. Furthermore, overprotection was positively related with rejection $(r=0.36, p<0.001)$ and emotional warmth $(r=0.18, p<0.001)$, and rejection was negatively related with emotional warmth $(r=-0.36$, $p<0.001$ ).

Multivariate models of inattention, hyperactivity, and impulsivity

Multiple linear regression analysis showed that FR-EXT, perceived parental styles and gender together explained $11 \%$ of the variance in parent-reported inattention (Table 3). There were main effects of FR-EXT (vs. no FR-EXT) (Fig. 1), emotional warmth, rejection, and overprotection, and gender, with boys having higher scores than girls. No significant interaction effects were found.

The model explained $9-12 \%$ of the variance in teacherrated inattention and hyperactivity/impulsivity. Main effects were found for FR-EXT, emotional warmth, overprotection, and gender. Two significant interactions were found for teacher-rated hyperactivity/impulsivity. A positive interaction effect was found between FR-EXT and

Table 2 Bivariate correlations between familial risk to externalizing behaviors, perceived parenting styles and externalizing behavior

\begin{tabular}{|c|c|c|c|c|c|c|c|c|}
\hline Variable & FR-EXT & CBCL-Inatt & TPC-Inatt & TCP-HA/IMP & CBCL-Aggr & TCP-Aggr & CBCL-Deli & TCP-Deli \\
\hline FR-EXT & - & $0.15^{* *}$ & $0.12 * *$ & $0.12 * *$ & $0.13 * *$ & $0.14 * *$ & $0.16 * *$ & $0.14 * *$ \\
\hline Emotional Warmth & ns & $-0.17 * *$ & $-0.19 * *$ & $-0.13 * *$ & $-0.16^{* *}$ & $-0.13 * *$ & $-0.15^{* *}$ & $-0.11 * *$ \\
\hline Rejection & ns & $0.20 * *$ & $0.15^{* *}$ & $0.16^{* *}$ & $0.27 * *$ & $0.13 * *$ & $0.23 * *$ & $0.08 * *$ \\
\hline Overprotection & $0.04 *$ & $0.12 * *$ & $0.10 * *$ & $0.10 * *$ & $0.13 * *$ & $0.10 * *$ & $0.11 * *$ & $0.07 * *$ \\
\hline
\end{tabular}

FR-EXT familial risk to externalizing behaviors, $C B C L$ child behavior checklist, $T C P$ teacher's checklist of psychopathology, Inatt inattention, $H A / I M P$ hyperactivity/impulsivity, Aggr aggression, Deli delinquency, $n s$ not significant

$* p<0.05 ; * * p<0.01$ (two-tailed) 
Table 3 Multiple regression analyses, for each separate (standardized) dependent variable and informant

\begin{tabular}{lccccccc}
\hline Variable & $\begin{array}{l}\text { CBCL-Inatt } \\
R^{2}=0.11\end{array}$ & $\begin{array}{l}\text { TPC-Inatt } \\
R^{2}=0.09\end{array}$ & $\begin{array}{l}\text { TCP-HA/IMP } \\
R^{2}=0.12\end{array}$ & $\begin{array}{l}\text { CBCL-Aggr } \\
R^{2}=0.11\end{array}$ & $\begin{array}{l}\text { TCP-Aggr } \\
R^{2}=0.10\end{array}$ & $\begin{array}{l}\text { CBCL-Deli } \\
R^{2}=0.12\end{array}$ & $\begin{array}{l}\text { TCP-Deli } \\
R^{2}=0.08\end{array}$ \\
\hline FR-EXT vs. no FR-EXT & $0.42(0.06)^{* *}$ & $0.22(0.06)^{* *}$ & $0.25(0.06)^{* *}$ & $0.36(0.06)^{* *}$ & $0.32(0.06)^{* *}$ & $0.47(0.06)^{* *}$ & $0.38(0.06)^{* *}$ \\
Emotional warmth & $-0.11(0.03)^{* *}$ & $-0.18(0.03)^{* *}$ & $-0.11(0.03)^{* *}$ & $-0.07(0.03)^{* *}$ & $-0.11(0.03)^{* *}$ & $-0.07(0.03)^{*}$ & $-0.12(0.03)^{* *}$ \\
Rejection & $0.09(0.03)^{* *}$ & $0.02(0.03)$ & $0.04(0.03)$ & $0.22(0.03)^{* *}$ & $-0.03(0.03)$ & $0.17(0.03)^{* *}$ & $-0.04(0.03)$ \\
Overprotection & $0.11(0.03)^{* *}$ & $0.11(0.03)^{* *}$ & $0.09(0.03)^{* *}$ & $0.06(0.03)^{*}$ & $0.09(0.03)^{* *}$ & $0.05(0.03)$ & $0.07(0.03)^{* *}$ \\
FR-EXT x emotional warmth & $-0.10(0.07)$ & $0.03(0.07)$ & $0.11(0.06)$ & $-0.10(0.07)$ & $0.05(0.07)$ & $-0.07(0.07)$ & $0.05(0.07)$ \\
FR-EXT $\times$ rejection & $0.07(0.07)$ & $0.04(0.07)$ & $0.15(0.07)^{*}$ & $-0.08(0.07)$ & $-0.01(0.07)$ & $0.01(0.07)$ & $0.16(0.07)^{*}$ \\
FR-EXT $\times$ overprotection & $-0.04(0.07)$ & $-0.02(0.07)$ & $-0.14(0.06)^{*}$ & $0.07(0.07)$ & $0.00(0.07)$ & $0.02(0.07)$ & $0.02(0.07)$ \\
Boys vs. girls & $0.27(0.04)$ & $0.34(0.04)^{* *}$ & $0.53(0.04)^{* *}$ & $0.19(0.04)^{* *}$ & $0.44(0.04)^{* *}$ & $0.33(0.04)^{* *}$ & $0.35(0.05)^{* *}$ \\
\hline
\end{tabular}

Values are expressed as $B(\mathrm{SE})$

FR-EXT familial risk to externalizing behaviors, $C B C L$ child behavior checklist, TCP teacher's checklist of psychopathology, Inatt inattention, HA/IMP hyperactivity/impulsivity, Aggr aggression, Deli delinquency

$* p<0.05 ; * * p<0.01$

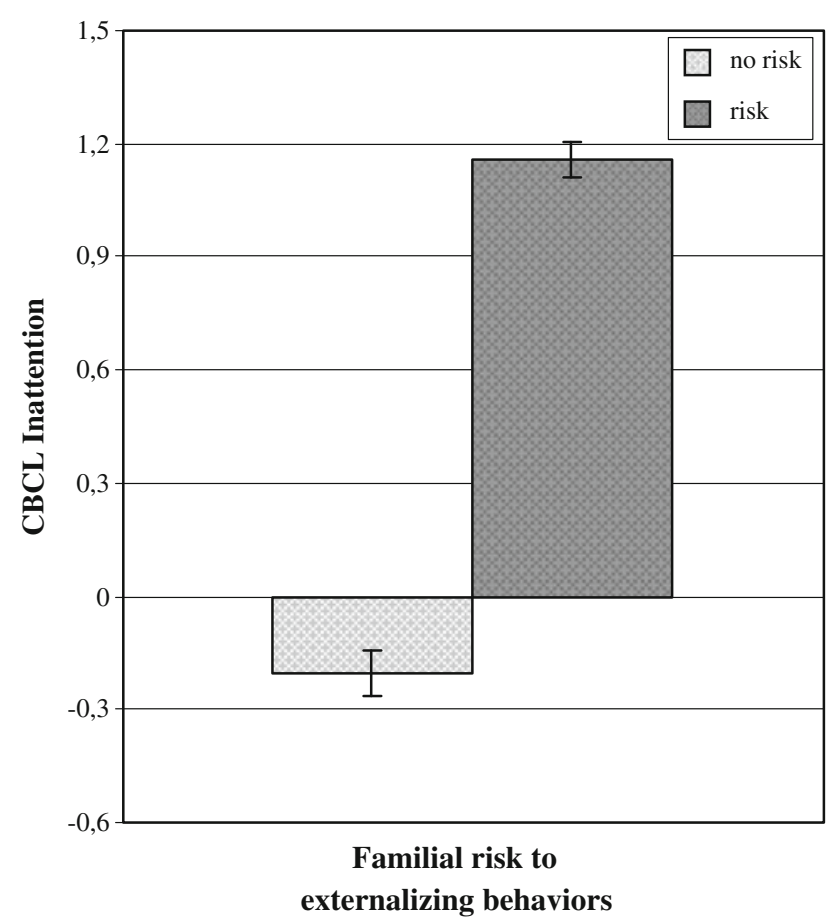

Fig. 1 Main effect of familial risk to externalizing behaviors (FREXT) as predictor of parent-reported inattention. Note The $Y$-axis represent the predicted means of the standardized CBCL score

rejection, indicating that children with FR-EXT were more vulnerable for parental rejection in exhibiting more hyperactive and impulsive behavior than children with no FR-EXT (Fig. 2). In contrast, a negative interaction effect was found between FR-EXT and overprotection. This means that the effect of parental overprotection was stronger for children with no FR-EXT, than for children with FR-EXT (Fig. 3).

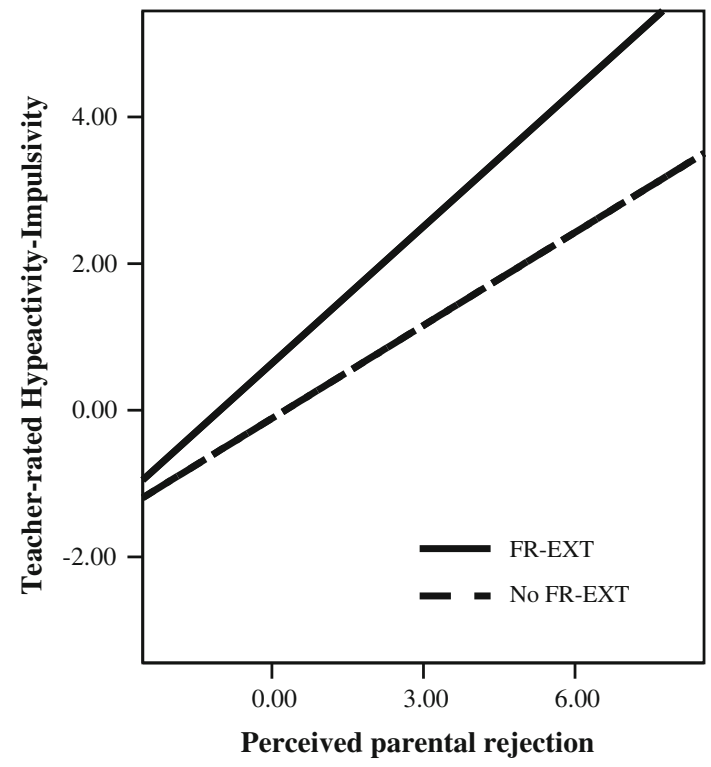

Fig. 2 Interaction effect between familial risk to externalizing behaviors (FR-EXT) and parental rejection as predictor of teacherreported hyperactivity and impulsivity. Note The $Y$-axis represent the predicted means of the standardized TCP score, the $X$-axis the standardized score on the specific subscale of the EMBU

Multivariate models of aggressive behavior

The models explained 11 and $10 \%$ of the variance in aggressive behavior reported by parents and teachers, respectively (Table 2). Main predictors of parent-rated aggression were FR-EXT, emotional warmth, rejection, overprotection, and gender. Main predictors of teacherrated aggression were FR-EXT, emotional warmth, overprotection, and gender. 


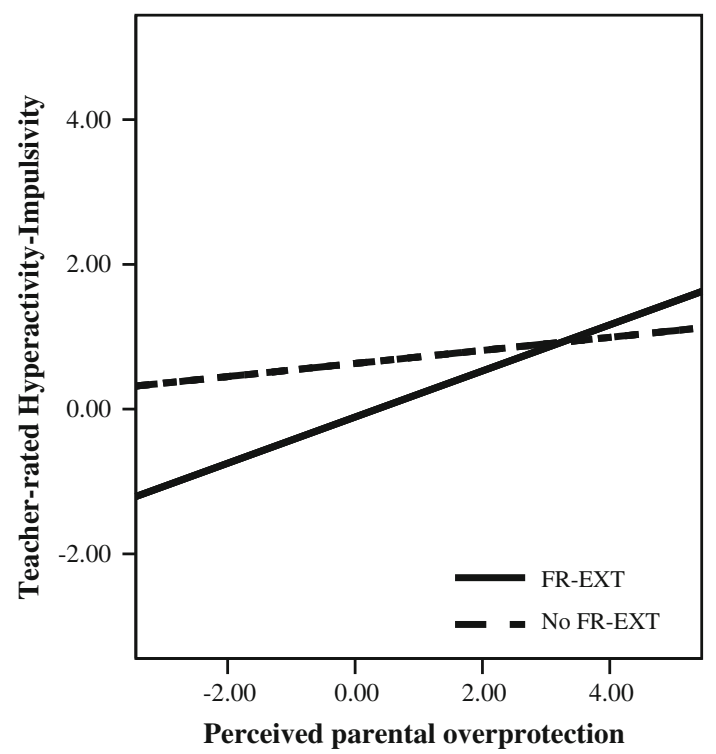

Fig. 3 Interaction effect between familial risk to externalizing behaviors (FR-EXT) and parental overprotection as predictor for teacher-reported hyperactivity and impulsivity. Note The $Y$-axis represent the predicted means of the standardized TCP score, the $X$ axis the standardized score on the specific subscale of the EMBU

Multivariate models of delinquent behavior

Parent-rated delinquent behavior could be explained by FR-EXT, emotional warmth, rejection, and gender (Table 2). These factors together explained $12 \%$ of the variance. The results for teacher-rated delinquent behaviors were comparable: FR-EXT, low levels of emotional warmth, high levels of overprotection, and male gender were main risk factors. One interaction effect was found between FR-EXT and rejection: children with FR-EXT were more vulnerable for parental rejection in showing more delinquent behavior than children with no FR-EXT.

\section{Discussion}

The study was set up on the premise that familial risk to externalizing behaviors (FR-EXT) and perceived parenting styles are main predictors of externalizing behaviors in preadolescents, and interact with each other. In line with earlier studies [9, 26, 43], we found FR-EXT to be a risk factor for externalizing behaviors in preadolescents, as evidenced by significant bivariate correlations between FREXT and all seven dependent measures of externalizing behaviors. In addition, in multivariate analyses, we found that FR-EXT was a main risk factor for the whole range of externalizing behaviors.

Beside the main effect of FR-EXT, three perceived parenting styles (emotional warmth, rejection, and overprotection) were found to be main predictors of externalizing behaviors, even after adjustment for other predictors in our multivariate models. In general, preadolescents who perceived a lack of parental emotional warmth, and high levels of parental rejection and overprotection were described as being more inattentive, aggressive, and delinquent by both parents and teachers. These findings are in line with other research [35]. In addition, perceived parental rejection had a greater effect on aggression and delinquent behavior than on inattention, impulsivity, and hyperactivity [23]. However, the effect of perceived parental rejection was present for parent-rated and not teacher-rated behavior. This finding may be explained by the fact parents and children are $50 \%$ genetically related. Therefore, the genetic influences of parent's and children's behavior may interact with each other and evoke negative parenting, which in turn, increases the likelihood of behavioral problems.

Our study design enabled us to determine the presence of gene-environment correlation and interaction on externalizing behaviors. We did not find correlations between FR-EXT and parental emotional warmth or rejection, and only a weak correlation between FR-EXT and parental overprotection. This indicates that FR-EXT and parenting styles seem to be two independent dimensions. This finding is in contrast with the idea that people modify and select their own environments, which results in (re)active geneenvironment correlations [37, 38]. With regard to the moderating effects, we entered three interaction terms in seven multivariate analyses, and found three to be significant. Although this number of significant interactions is at change level ( $n=21$, test proportion $0.05, p<0.10$ by binomial test), these interactions seem to be meaningful. The interactions between FR-EXT and perceived parental rejection was significant for both teacher-rated hyperactivity and teacher-rated delinquency. This indicates that children with FR-EXT are more susceptible for parental rejection in showing more hyperactive/impulsive and delinquent behavior than children with no FR-EXT. Another interaction between FR-EXT and overprotection was significant for teacher-rated hyperactivity/impulsivity, indicating that children with no FR-EXT were more susceptible for parental overprotection. These findings are similar to results reported in studies of temperamentenvironment interactions, and problem behavior [25, 43]: perceived parental rejection and overprotection interacted both with temperament in predicting depressive and delinquent behaviors in preadolescence, respectively.

Our unexpected finding, that virtually no gene-environment correlation and only a few gene-environment interactions were present, may be explained in several ways. First, FR-EXT was defined at a phenotypic level and was based on family history as a proxy for genetic vulnerability. With the caveat in mind that FR-EXT may 
reflect both genetic and environmental influences, the availability of DNA analysis in the next future will allow us to refine our analyses by including genetic polymorphisms as risk factors. Second, the use of family history interviews, when compared with direct interviews of relatives, may have led to underreporting of lifetime parental psychopathology, and thus underestimation of associations is possible [26]. However, except for father's rate for substance dependence, our prevalence rates were comparable to life time rates obtained by direct interviewing [7]. Third, we used a community sample, covering a wide range of environments and parenting styles; however, specific environments or parenting styles may have a more negative impact than other environments or styles [34, 40]. Therefore, future studies should include clinical samples and more extreme parenting styles. Fourth, we evaluated parenting style in terms of the child's perception, which may have been influenced by the child's own FR-EXT. Though the level of FR-EXT is reported by the parent, the genetic make-up of the child may be related with their own mental representation regarding parenting styles of their parents. In that way the genetic make-up of the child is discounted in the perception of the child, which may have resulted in and underestimation of gene-environment correlations. Lastly, we looked at the effect of perceived parenting in preadolescents but greater effects may be found in younger children $[6,17]$. Moreover, it should be borne in mind that attention problems, aggression, and delinquent behavior are heterogeneous problem behaviors that may have different biological and etiological backgrounds.

\section{Conclusion}

FR-EXT and perceived parenting styles independently affected the expression of parent- and teacher-rated externalizing behaviors and can be seen as two relatively independent areas of causation in a population based sample of preadolescents. However, some environmental moderation of FR-EXT is present, albeit of a small effect. Further research is necessary to study whether our findings hold for more extreme forms of parenting styles and for longitudinal analyses of externalizing behaviors throughout adolescence.

Acknowledgments This research is part of TRAILS, a multicenter cohort study involving the University of Groningen, the Erasmus Medical Center of Rotterdam, the Vrije University of Amsterdam, the Radboud University Nijmegen Medical Centre, and the Trimbos Institute and the University of Leiden, the Netherlands. TRAILS is financially supported by grants from the Netherlands Organization for Scientific Research (GB-MW 940-38-011, GB-MAG 480-01-006, ZonMw 100.001.001; NWO-175.010.2003.005) and the Department of Justice, and by the participating centers. C.J.M. Buschgens is supported by Radboud University Nijmegen Medical Centre.
Open Access This article is distributed under the terms of the Creative Commons Attribution Noncommercial License which permits any noncommercial use, distribution, and reproduction in any medium, provided the original author(s) and source are credited.

\section{References}

1. Achenbach TM (1991) Manual for the child behavior checklist/4 18 and 1991 profile. University of Vermont, Burlington

2. Achenbach TM, Mc Conaughy SH, Howell CT (1987) Child/ adolescent behavioral and emotional problems: implications of cross-informant correlations for situational specificity. Psychol Bull 101:213-232

3. American Psychiatric Association (1994) Diagnostic and statistical manual of mental disorders, 4th edn. American Psychiatric Association, Washington

4. Barnow S, Schuckit M, Smith TL, Preuss U, Danko G (2002) The relationship between the family density of alcoholism and externalizing symptoms among 146 children. Alcohol Alcohol 37:383-387

5. Belsky J, Bakermans-Kranenburg MJ, van IJzendoorn MH (2007) For better and for worse. Differential susceptibility to environmental influences. Curr Dir Psychol Sci 16:300-304

6. Belsky J, Hsieh KH, Crnic K (1998) Mothering, fathering, and infant negativity as antecedents of boys' externalizing problems and inhibition at age 3 years: differential susceptibility to rearing experience? Dev Psychopathol 10:301-319

7. Bijl RV, Ravelli A, Van Zessen G (1998) Prevalence of psychiatric disorder in the general population: results of The Netherlands Mental Health Survey and Incidence Study (NEMESIS). Soc Psychiatry Psychiatr Epidemiol 33:587-595

8. Burt SA, Krueger RF, McGue M, Iacono W (2003) Parent-child conflict and the comorbidity among childhood externalizing disorders. Arch Gen Psychiatry 60:505-513

9. Buschgens CJM, Swinkels SHN, Van Aken MAG, Ormel J, Verhulst FC, Buitelaar JK (2009) Externalizing behaviors in preadolescents: familial risk to externalizing behavior, prenatal and perinatal risks, and their interactions. Eur Child Adolesc Psychiatry 18:65-74

10. Dick DM, Aliev F, Wang JC, Grucza RA, Schuckit M, Kuperman S, Kramer J, Hinrichs A, Bertelsen S, Budde JP, Hesselbrock V, Porjesz B, Edenberg HJ, Bierut LJ, Goate A (2008) Using dimensional models of externalizing psychopathology to aid in gene identification. Arch Gen Psychiatry 65:310-318

11. De Winter AF, Oldehinkel AJ, Veenstra R, Brunnekreef JA, Verhulst FC, Ormel J (2005) Evaluation of non-response bias in mental health determinants and outcomes in a large sample of pre-adolescents. Eur J Epidemiol 20:173-181

12. Deater-Deckard K, Dodge KA (1997) Externalizing behavior problems and discipline revisited: nonlinear effects and variation by culture, context and gender. Psychol Inq 8:161-175

13. Deater-Deckard K, Plomin R (1999) An adoption study of the etiology of teacher and parent reports of externalizing behavior problems in middle childhood. Child Dev 70:144-154

14. Hicks BM, Krueger RF, Iacono WG, McGue M, Patrick CJ (2004) Family transmission and heritability of externalizing disorders: a twin-family study. Arch Gen Psychiatry 61:922-928

15. Katz MH (1999) Multivariate analysis. A practical guide for clinicians. Cambridge University Press, New York

16. Kendler KS, Prescott CA, Myers J, Neale MC (2003) The structure of genetic and environmental risk factors for common psychiatric and substance use disorders in men and women. Arch Gen Psychiatry 60:929-937 
17. Kochanska G (1997) Multiple pathways to conscience for children with different temperaments: from toddlerhood to age 5 . Dev Psychol 33:228-240

18. Maccoby EE, Martin JA (1983) Socialization in the context of the family: parent-child interaction. In: Mussen P (ed) Handbook of child psychology, vol. IV. Socialization, personality and social development. Wiley, New York, pp 1-101

19. Markus MTh, Lindhout IE, Boer F, Hoogendijk THG, Arrindell WA (2003) Factors of perceived parental rearing styles: the EMBU-C examined in a sample of Dutch primary school children. Pers Individ Differ 34:503-519

20. Meesters C, Muris P, Esselink T (1995) Hostility and perceived parental rearing behavior. Pers Divid Differ 18:567-570

21. Moffitt TE (2005) The new look of behavioral genetics in developmental psychopathology: gene-environment interplay in antisocial behaviors. Psychol Bull 131:533-554

22. Muris P, Meesters C, Van Brakel A (2003) Assessment of anxious rearing behaviors with a modified version of "Egna Minnen Beträffande Uppfostran” questionnaire for children. J Psychol Behav Assess 25:229-237

23. Muris P, Meesters C, van den Berg S (2003) Internalizing and externalizing problems as correlates of self-reported attachment style and perceived parental rearing in normal adolescents. J Child Fam Stud 12:171-183

24. Nadder TS, Rutter M, Silberg JL, Maes HH, Eaves LJ (2002) Genetic effects on the variation and covariation of attention deficit-hyperactivity disorder (ADHD) and oppositional-defiant disorder/conduct disorder (ODD/CD) symptomatologies across informant and occasion of measurement. Psychol Med 32:39-53

25. Oldehinkel AJ, Veenstra R, Ormel J, de Winter AF, Verhulst FC (2006) Temperament, parenting, and depressive symptoms in a population sample of preadolescents. J Child Psychol Psychiatry 47:684-695

26. Ormel J, Oldehinkel AJ, Ferdinand RF, Hartman CA, De Winter AF, Veenstra R, Vollebergh W, Minderaa RB, Buitelaar JK, Verhulst FC (2005) Internalizing and externalizing problems in adolescence: general and dimension-specific effects of familial loadings and preadolescent temperament traits. Psychol Med 35:1825-1835

27. Plomin R (1995) Genetics and children's experiences in the family. J Child Psychol Psychiatry 36:33-68

28. Plomin R (2005) Genetics and developmental psychology. Merill-Palmer Q 50:341-352

29. Plomin R, McClearn GE, Pedersen NL, Nesselroade JR, Bergeman CS (1988) Genetic influence on childhood family environment perceived retrospectively from the last half of the life span. Dev Psychol 24:738-745
30. Plomin R, Rutter M (1998) Child development, molecular genetics, and what to do with genes once they are found. Child Dev 69:1223-1242

31. Rietveld MJ, Hudziak JJ, Bartels M, van Beijsterveldt CE, Boomsma DI (2004) Heritability of attention problems in children: longitudinal results from a study of twins, age 3 to 12 . J Child Psychol Psychiatry 45:577-588

32. Rowe DC (1981) Environmental and genetic influences on dimensions of perceived parenting: a twin study. Dev Psychol 17:203-208

33. Rowe DC (1983) A biometrical analysis of perceptions of family environment: a study of twin and singleton siblings. Child Dev $54: 416-423$

34. Rowe DC (1994) The limits of family influence: genes, experience, and behavior. The Guilford Press, New York

35. Ruchkin VV, Eisemann M, Hägglöf B (1998) Parental rearing and problem behaviors in male delinquents versus controls in northern Russia. Soc Psychiatry Psychiatr Epidemiol 33:477-482

36. Rutter M (2002) The interplay of nature, nurture, and developmental influences: the challenge ahead for mental health. Arch Gen Psychiatry 59:996-1000

37. Rutter M, Dunn J, Plomin R, Simonoff E, Pickles A, Maughan B, Ormel J, Meyer J, Eaves L (1997) Integrating nature and nurture: implications of person-environment correlations and interactions for developmental psychopathology. Dev Psychopathol 9:335-364

38. Rutter M, Silberg J (2002) Gene-environment interplay in relation to emotional and behavioral disturbance. Annu Rev Psychol 53:463-490

39. Rutter M, Silberg J, O’Connor T, Simonoff E (1999) Genetics and child psychiatry: II empirical research findings. J Child Psychol Psychiatry 40:19-55

40. Scarr S, Weinberg RA (1978) The influence of "family background" intellectual attainment. Am Soc Rev 43:674-692

41. Spera C (2005) A review of the relationship among parenting practices, parenting styles, and adolescent school achievement. Educ Psychol Rev 17:125-146

42. Van der Valk JC, van den Oord EJ, Verhulst FC, Boomsma DI (2003) Using shared and unique parental views to study the etiology of 7-year-old twins' internalizing and externalizing problems. Behav Genet 33:409-420

43. Veenstra R, Lindenberg S, Oldehinkel AJ, de Winter AF, Ormel J (2006) Temperament, environment, and antisocial behavior in a population sample of preadolescent boys and girls. Int J Behav Dev 30:422-432

44. Verhulst FC, Achenbach TM (1995) Empirically based assessment and taxonomy of psychopathology: cross-cultural applications. Eur Child Adolesc Psychiatry 4:61-76 